\title{
SKIN AND SOFT TISSUE INFECTIONS: BACTERIOLOGICAL PROFILE AND ANTIBIOTIC RESISTANCE PATTERN OF ISOLATES
}

\author{
Sah P. ${ }^{1}$, Khanal R. ${ }^{2}$, Upadhaya $S .^{3}$
}

\section{ABSTRACT}

INTRODUCTION: Emergence and spread of antibiotic resistance in organisms causing skin and soft tissue infections (SSTIs) is posing a great therapeutic challenge. This study aimed to determine bacteriology of SSTIs and study antibiotic resistance among the isolates.

MATERIAL AND METHODS: A retrospective analysis of 149 consecutive pus specimens received at microbiology laboratory of Universal College of Medical Sciences \& Teaching Hospital, Bhairahawa over a period of 8 months from July 2012 to February 2013 was done. The bacterial isolates were identified by standard microbiological techniques and antibiotic susceptibility testing was done by Modified Kirby-Bauer method.

RESULTS: Growth was seen in 92 (62\%) specimens out of which 88 specimens yielded single isolate and 4 specimens yielded 2 isolates. Hence a total of 96 isolates were isolated. The commonest isolates were Staphylococcus aureus (n=39) followed by E. coli (n=11), Pseudomonas spp (n=11), Coagulase negative staphylococci (n=9), Klebsiella spp (n=6), Proteus $\operatorname{spp}(\mathrm{n}=5)$, Streptococcus $\operatorname{spp}(\mathrm{n}=4)$, Acinetobacter $\operatorname{spp}(\mathrm{n}=1)$, and unidentified gram negative bacilli $(\mathrm{n}=10)$. Among gram positive cocci susceptibility to Amikacin was highest followed by vancomycin and gentamycin. Among gram negative bacilli aminoglycosides and ciprofloxacin susceptibility was high, however all $E$. coli isolates were ciprofloxacin resistant. Majority of isolates were resistant to amoxicillin, ceftriaxone and cotrimoxazole.

CONCLUSION: In conclusion this study reports the commonest organism in SSTIs is $S$. aureus followed by E.coli and Pseudomonas spp. Continued monitoring of susceptibility pattern need to be carried out to detect the true burden of antibiotic resistance in organisms and prevent their further emergence by judicious use of drugs.

KEY WORDS: Skin and soft tissue infections, Antibiotic resistance, S. aureus

${ }^{1,2,3}$ Lecturer, Department of Microbiology, Universal College of Medical Sciences \& Teaching Hospital, Bhairahawa, Nepal

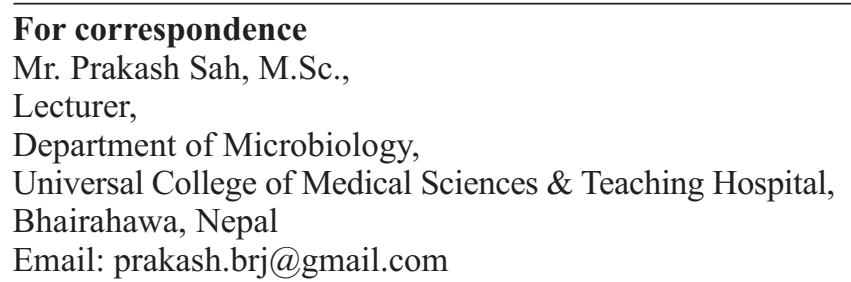




\section{INTRODUCTION}

Skin and soft-tissue infections (SSTIs) are a common presenting problem in both inpatients and outpatients. SSTIs may range from simple uncomplicated superficial infections such as folliculitis, cellulitis, and abscesses to deeper complicated infections such as necrotizing fasciitis, burn infections and diabetic foot. ${ }^{1}$ Complicated SSTIs contribute to longer hospital stays, increase in the cost of medical care and are likely to have a significant role in the development of antimicrobial resistance. ${ }^{2,3}$ Improperly treated SSTIs may lead to development of complications that include endocarditis, osteomyelitis, brain abscess or meningitis, lung abscess, or pneumonia. ${ }^{4}$ The most common organisms likely to be encountered in soft tissue infections are gram-positive cocci, notably $S$. aureus, followed by gram negative bacilli such as $E$. coli, Pseudomonas, Proteus etc. among other organisms. ${ }^{5,6}$

Superficial SSTIs are generally treated on an outpatient basis with oral antibiotics and topical care. ${ }^{7}$ However, complicated SSTIs involving deeper layers like fascia and muscle can rapidly progress to systemic sepsis and prove fatal. ${ }^{2}$ These are the type of infections that require a wise choice of antimicrobials in addition to aggressive surgical debridement to limit tissue loss and preserve life. ${ }^{2,8}$ While as definitive antimicrobial therapy should be based on cultured organisms and their susceptibility, the dilemma of starting empiric therapy with a narrow-spectrum agent, a broad spectrum agent, or one that covers resistant organisms continues to persist. Hence, it is important to know the prevailing susceptibility patterns of bacterial isolates at individual institutions by routine surveillance. This retrospective study was therefore carried out to investigate the agents responsible for soft tissue infections and study their antimicrobial susceptibility at Universal College of medical sciences and teaching hospital.

\section{METHODS}

A retrospective analysis of 149 consecutive pus specimens received at microbiology laboratory of Universal College of medical sciences and teaching hospital, Bhairahawa over a period of 8 months from July 2012 to February 2013 was done. The aspirate specimens were transported in sterile, leakproof containers and swabs were obtained on sterile cotton swabs (Hi-media) and were processed immediately in the laboratory. All specimens were inoculated onto Nutrient agar, Blood agar and MacConkey agar (Hi-media) and incubated aerobically overnight at $37^{\circ} \mathrm{C}$. Bacterial isolates were identified based on colony morphology, gram's stain and conventional biochemical tests following standard microbiological techniques. Antibiotic susceptibility testing was done using Mueller-Hinton agar (Hi-media) by the modified Kirby-Bauer method as recommended by CLSI.

\section{RESULTS}

A total of 149 pus specimens were received at the laboratory during the study period. 80 (54\%) specimens were from male and $69(46 \%)$ were from female patients. The mean age of patients was 33 years ranging from newborn to 79 years. Majority $(78 \%)$ of the specimens were received from the wards of surgery, orthopedics, ENT and Opd. Out of 149 specimens $92(62 \%)$ showed growth while 57 (38\%) specimens did not show any growth. Highest culture positivity was found among specimens from ENT (78\%) followed by gynecology and surgery wards (figure 1).

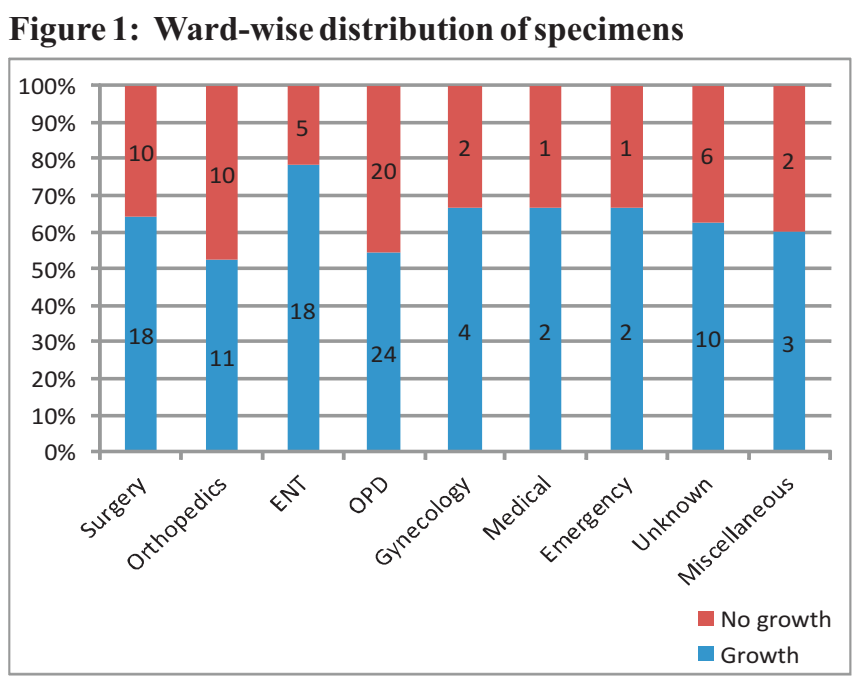

Mixed growth ( 2 isolates) was found among 4 culture positive specimens while 88 specimens showed growth of single isolate. Hence a total 96 bacterial isolates were isolated from culture positive specimens. The commonest isolates were gram positive cocci, mainly $S$. aureus $(\mathrm{n}=39)$ followed by gram negative bacilli such as E. coli $(\mathrm{n}=11)$, Pseudomonas spp $(\mathrm{n}=11)$ (figure 2).

Figure 2: Bacteriological profile of pus specimen

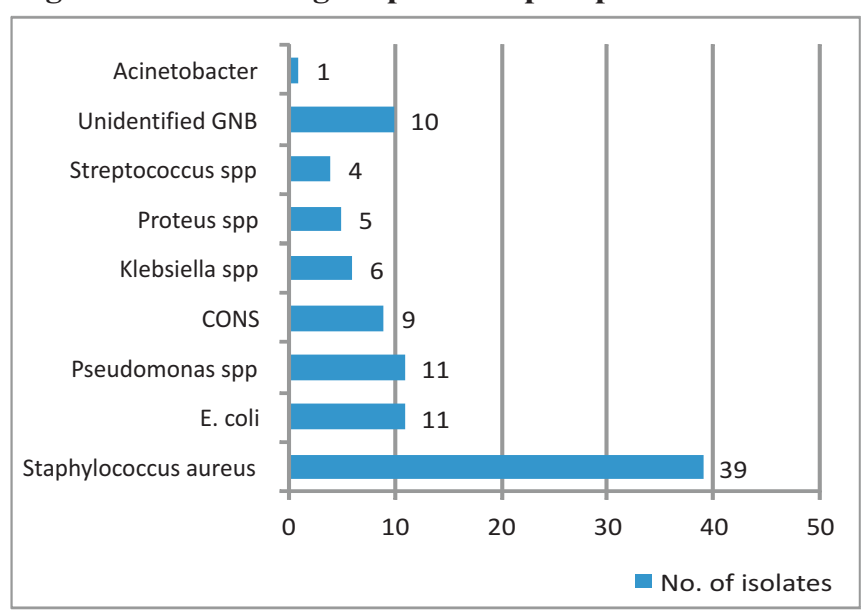


Other isolates included Coagulase negative staphylococci ( $\mathrm{n}=9)$, Streptococcus $\mathrm{spp}(\mathrm{n}=4)$, Klebsiella $\mathrm{spp}(\mathrm{n}=6)$, Proteus spp $(n=5)$, Acinetobacter spp $(n=1)$, and unidentified gram negative bacilli $(n=10)$. All gram positive cocci showed complete susceptibility to amikacin followed by vancomycin and gentamycin. Amoxicillin and cefepime resistance was highest followed by cotrimoxazole, ceftriaxone and ciprofloxacin (table 1).

Table 1: Antibiotic resistance pattern of Gram positive cocci

\begin{tabular}{|l|l|l|l|}
\hline Antibiotics $(\boldsymbol{\mu g} / \mathbf{d i s c})$ & S. aureus & CONS & Streptococcus spp \\
\hline Amoxycillin (30) & $89.47 \%(19)$ & $100 \%(3)$ & $100 \%(1)$ \\
\hline Amikacin (30) & $0 \%(38)$ & $0(9)$ & $0 \%(4)$ \\
\hline Chloramphenicol (30) & $10.53 \%(19)$ & $14.28 \%(7)$ & $33.33 \%(3)$ \\
\hline Cotrimoxazole (1.25/23.75) & $69.23 \%(13)$ & $100 \%(4)$ & $50 \%(2)$ \\
\hline Ceftriaxone (30) & $30 \%(20)$ & $50 \%(4)$ & $50 \%(2)$ \\
\hline Ciprofloxacin (5) & $29.41 \%(17)$ & $33.33 \%(3)$ & $50 \%(2)$ \\
\hline Cefepime (30) & $90.90 \%(22)$ & $100 \%(7)$ & $100 \%(2)$ \\
\hline Erythromycin (15) & $26.92 \%(26)$ & $57.15 \%(7)$ & $50 \%(2)$ \\
\hline Gentamycin (10) & $18.18 \%(33)$ & $42.85 \%(7)$ & $0 \%(4)$ \\
\hline Vancomycin (30) & $5.56 \%(36)$ & $22.22 \%(9)$ & $0 \%(4)$ \\
\hline
\end{tabular}

Note: figures in parentheses indicate numbers of isolates tested

Higher rate of resistance was seen among coagulase negative staphylococci (CONS) isolates as compared to $S$. aureus among various groups of antibiotics tested. All gram negative bacilli were 100\% resistant to amoxicillin. Also higher rate of resistance was seen against cefepime followed by ceftriaxone and cefotaxime. Overall amikacin followed by ciprofloxacin and gentamycin showed excellent activity against these isolates. However all E. coli isolates tested were found to be resistant to ciprofloxacin. Also higher resistance among Klebsiella spp was seen against the aminoglycosides (table 2).

Table 2: Antibiotic resistance pattern of gram negative bacilli

\begin{tabular}{|l|l|l|l|l|l|l|}
\hline Antibiotics $(\boldsymbol{\mu g} / \mathrm{disc})$ & $\boldsymbol{E}$ coli & Pseudomonas & Klebsiella & Proteus & $\begin{array}{c}\text { Unidentified } \\
\text { GNB }\end{array}$ & Acinetobacter \\
\hline Amoxycillin (30) & $100 \%(8)$ & $100 \%(6)$ & $100 \%(4)$ & $100 \%(4)$ & $100 \%(4)$ & $100 \%(1)$ \\
\hline Amikacin (30) & $10 \%(10)$ & $0 \%(9)$ & $50 \%(4)$ & $0 \%(4)$ & $0 \%(8)$ & $100 \%(1)$ \\
\hline Chloramphenicol(30) & $40 \%(5)$ & $25 \%(4)$ & $75 \%(4)$ & $33.33 \%(3)$ & $33.33 \%(6)$ & $100 \%(1)$ \\
\hline $\begin{array}{l}\text { Cotrimoxazole } \\
(1.25 / 23.75)\end{array}$ & $100 \%(6)$ & $100 \%(4)$ & ND & $100 \%(3)$ & $75 \%(4)$ & $100 \%(1)$ \\
\hline Cefotaxime (30) & $66.67 \%(3)$ & ND & ND & ND & $50 \%(2)$ & $100 \%(1)$ \\
\hline Ceftriaxone (30) & $71.42 \%(7)$ & $33.33 \%(6)$ & $66.67 \%(3)$ & $100 \%(1)$ & $33.33 \%(3)$ & ND \\
\hline Ciprofloxacin (5) & $100 \%(6)$ & $0 \%(7)$ & $20 \%(5)$ & $0 \%(2)$ & $0 \%(3)$ & ND \\
\hline Cefepime (30) & $100 \%(9)$ & $88.89 \%(9)$ & $100 \%(6)$ & $100 \%(3)$ & $50 \%(6)$ & $100 \%(1)$ \\
\hline Gentamycin (10) & $33.33 \%(9)$ & $20 \%(10)$ & $50 \%(6)$ & $0 \%(5)$ & $0 \%(8)$ & $100 \%(1)$ \\
\hline Ofloxacin (5) & $66.67 \%(3)$ & ND & ND & $0 \%(1)$ & $40 \%(5)$ & $100 \%(1)$ \\
\hline
\end{tabular}

Note: figures in parentheses indicate numbers of isolates tested 


\section{DISCUSSION}

In present study the culture positivity rate was $62 \%$ with most of the culture positive specimens showing growth of single isolate which is comparable to various studies reported from India. 5, 6, 9 The predominant isolate was S.aureus highest followed by E.coli, Pseudomonas spp, Klebsiella spp and Proteus spp similar to findings of studies from India and abroad. $3,5,6,9$

Among S. aureus isolates amoxicillin resistance (89.47\%) was high similar to earlier report from same hospital. ${ }^{10}$ Cotimoxazole resistance $(69.23 \%)$ was similar to study by Gupta $e^{2} a l^{6}$ and Najotra et $a l^{9}$. Erythromycin resistance among $S$. aureus has decreased at our hospital as indicated by a lower resistance $(26.92 \%)$ in this study as compared to study by Tiwari et $a l .{ }^{10}$ Resistance to ciprofloxacin (29.41\%) and ceftriaxone $(30 \%)$ were also relatively high. There is a high prevalence of Methicillin resistant $S$. aureus (MRSA) at our hospital. ${ }^{10}$ This may be the reason for occurrence of higher resistance towards beta lactams and other group of antibiotics among S.aureus. However, susceptibilities to Amikacin, vancomycin and gentamycin remain high in this study.

Among gram negative bacilli highest resistance was seen against amoxicillin (100\%). Resistance towards third generation cephalosporins- cefepime $(50 \%$ to $100 \%)$, cefotaxime $(50 \%$ to $100 \%)$, ceftriaxone $(33.33 \%$ to $100 \%)$ was also high. This may be because of increasing expression of extended spectrum beta-lactamases (ESBLs) among gram negative bacilli. Ciprofloxacin susceptibility was high against all gram negative bacilli except $E$. coli for which resistance was $100 \%$. Najotra [et al] ${ }^{9}$ has also reported higher ciprofloxacin resistance among E.coli. Aminoglycosides also showed good susceptibility against these isolates; however Klebsiella isolates showed a higher (50\%) resistance as compared to other isolates.

The higher rates of resistance may be attributed to the fact that ours is a tertiary care hospital with widespread use of broadspectrum antibiotics leading to selective survival advantage of pathogens and lack of definite antibiotic policy which is a matter of great concern.

\section{CONCLUSION}

In conclusion this study reports the commonest organism likely to be encountered in skin and soft tissue infections is $S$. aureus followed by E.coli and Pseudomonas spp. Aminoglycosides, ciprofloxacin and vancomycin could be used for empirical therapy to cover these organisms. However, in the view varied bacteriology and antibiogram of SSTIs definitive antibiotic therapy should be started as soon as possible based on susceptibility reports. Lastly, continued monitoring of susceptibility pattern need to be carried out so as to detect the true burden of antibiotic resistance in organisms and prevent their further emergence by judicious use of drugs.

\section{REFERENCES}

1. Rajan S. Skin and soft tissue infections: classifying and treating a spectrum. Cleveland journal of medicine 2012; 79:57-66.

2. Martone WJ, Nichols RL. Recognition, prevention, surveillance, and management of surgical site infections. Clin Infect Dis 2001; 33:S67-S106.

3. Sader HS, Jones RN, Silva JB. Skin and soft tissue infections in Latin American medical centers: four-year assessment of the pathogen frequency and antimicrobial susceptibility patterns. Diagn Microbiol Infect Dis 2002; 44:281-8.

4. Stevens $D l$, Smith $L G$, Bruss JB, Martin MA, Duvall SE, Todd WM. Ramdomized comparison of linezolid (PNU100766) versus Oxacillin-dicloxacillin for treatment complicated skin and soft tissue infections. Antimicrob Agents Chemother 2000; 44:3408-13.

5. Mohanty S, Kapil A, Dhawan B, Das BK. Bacteriological and antimicrobial susceptibility profile of soft tissue infections from Northern India. Indian J Med Sci 2004; 58:10-5.

6. Gupta V, Datta P, Singla N. Skin and soft tissue infections: Frequency of aerobic bacterial isolates and their antimicrobial susceptibility pattern. JAPI 2008;56:390-1

7. Nichols RL, Florman S. Clinical presentations of soft-tissue infections and surgical site infections. Clin Infect Dis 2001; 33:S84-93.

8. Singh G, Sinha K, Adhikari S, Babu SK, Ray P, Khanna SK. Necrotising infections of soft tissues - a clinical profile. Eur J Surg 2002; 168:366-71.

9. Najotra DK, Kakru DK. Bacteriology and antibiogram of skin and soft tissue infections from a tertiary care hospital. Indian journal of medical specialties 2012; 3(1):26-30.

10. Tiwari HK, Das AK, Sapkota D, Sivarajan K, Pahwa VK. Methicillin resistant Staphylococcus aureus: prevalence and antibiogram in a tertiary care hospital in western Nepal. JInfect Dev Ctries 2009; 3(9):68 